\title{
Simultaneous measurement of preductal and postductal oxygen saturation by pulse oximetry in hyaline membrane disease
}

\author{
P D Macdonald, V Y H Yu
}

\begin{abstract}
Preductal and postductal oxygen saturation were compared in 20 ventilated preterm infants with hyaline membrane disease to establish the frequency of right to left shunting and to assess the accuracy of postductus arteriosus blood gas sampling. One hundred and thirty eight comparisons were made and the frequency of right to left shunting was $17 \%(95 \%$ confidence interval 12 to $25 \%$ ). Shunting episodes with possible preductal hyperoxia occurred far less commonly on a maximum of $5 \%$ of occasions. The findings in infants under $1000 \mathrm{~g}$ and of 24-28 weeks' gestation were not significantly different from larger or more mature infants. Shunting occurred significantly more frequently in very ill infants who subsequently died as a result of respiratory disease.
\end{abstract}

\section{(Arch Dis Child 1992;67:1166-8)}

Ventilated premature infants require close monitoring of oxygenation. This is currently carried out by a variety of methods including blood gas analysis from different sites, transcutaneous monitoring of oxygen tension $\left(\mathrm{Po}_{2}\right)$ and oxygen saturation monitoring. With the exception of arterial blood samples taken from the right arm and saturation probes positioned at this site all these methods rely on sampling from areas perfused by postductus arteriosus blood flow. In the first day of life bidirectional shunting through the ductus may occur and this is often proposed as an explanation for a poor $\mathrm{Po}_{2}$. Such shunting has been clearly demonstrated in the past by invasive methods but mainly in relatively large babies who were predominantly not ventilated. ${ }^{12}$ If significant bidirectional or right to left shunting is occurring then blood perfusing the right subclavian and carotid arteries could have a substantially higher oxygen content than that being measured. This is obviously of greatest relevance in the smallest and most premature infants requiring ventilatory support and at greater risk of retinopathy of prematurity. With the exception of one previous study ${ }^{3}$ the problem of shunting in such infants has been largely ignored. Thus it is important to make a comparison of oxygenation at a preductal and postductal level in these small infants. The easiest and least invasive method of doing this is by the use of pulse oximeters; this method has been used previously to document right to left shunting in the first minutes of life during resuscitation of newborn infants. ${ }^{4}$

The aim of this study was to identify the frequency of right to left ductal shunting at the time when postductal arterial blood gas samples are obtained and to assess the reliability of such samples.

\section{Patients and methods}

Infants of 32 weeks' gestation and under were recruited to the study if they required early ventilation for hyaline membrane disease and had either an umbilical arterial catheter or a peripheral arterial line sited in a lower limb artery. During the first 36 hours of life recordings of oxygen saturation were made when arterial blood gases were checked. Immediately before obtaining a blood sample Ohmeda Biox 3700 pulse oximeters were attached to the right arm and either foot. To avoid movement artefact the pulse waveform was observed until there was a strong steady signal with a pulse rate that matched that on the cardiac monitor. It usually required five minutes for the infant to settle and the signals to stabilise. When there was a reliable signal from each monitor a blood sample was taken and the saturation readings recorded. All samples were obtained and recordings made by a single observer (PDM). The oximeter probes were shielded from extraneous light to avoid interference.

In the initial studies (first 10 patients and 76 measurements) the monitor positions were switched whenever a saturation discrepancy was noted. As this consistently gave the same result this practice was abandoned in the later studies to minimise disturbance to the babies. A saturation in the right arm of at least 3\% above the lower limb was taken to indicate right to left ductal shunting. Such a difference represents a right to left ductal shunt of approximately $10 \%$ of the postductal blood flow assuming normal mixed venous saturation. ${ }^{5}$

\section{Results}

Twenty infants were enrolled in the study with a mean birth weight of $1095 \mathrm{~g}$ (range 660-1750). The mean gestation was $27 \cdot 7$ weeks (range 24-32 weeks). All were ventilated for hyaline membrane disease within six hours of birth. A total of 138 comparisons were made ranging from four to 11 for each infant (mean 6.9 for each infant). Eight of the 
Table 1. Upper limits of $\mathrm{PaO}_{2}$ at given lower limb saturation

\begin{tabular}{llll}
\hline $\begin{array}{l}\text { Lower limb } \\
\text { postductal } \\
\text { saturation (\%) }\end{array}$ & $\begin{array}{l}\text { No of } \\
\text { infants }\end{array}$ & \multicolumn{2}{c}{ Postductal $\mathrm{PaO}_{2}(\mathrm{kPa})$} \\
\cline { 3 - 4 } & & Mean & Mean+1.645 SD \\
\hline $99-100$ & 4 & $15 \cdot 1$ & $18 \cdot 0$ \\
$97-98$ & 12 & $10 \cdot 9$ & $16 \cdot 4$ \\
$95-96$ & 20 & $8 \cdot 8$ & $13 \cdot 2$ \\
$93-94$ & 26 & $8 \cdot 8$ & $11 \cdot 5$ \\
$91-92$ & 27 & $7 \cdot 8$ & $10 \cdot 4$ \\
$89-90$ & 16 & $7 \cdot 9$ & $10 \cdot 2$ \\
$87-88$ & 12 & $6 \cdot 9$ & $8 \cdot 9$ \\
$85-86$ & 7 & $6 \cdot 3$ & $7 \cdot 3$ \\
$81-84$ & 6 & $6 \cdot 0$ & $7 \cdot 5$ \\
$70-80$ & 4 & $5 \cdot 6$ & $6 \cdot 7$ \\
$<70$ & 4 & & \\
\hline 70
\end{tabular}

20 infants weighed under $1000 \mathrm{~g}$ at birth and 11 of the 20 were born at 24-28 weeks' gestation. An initial comparison was made of arterial oxygen tension $\left(\mathrm{PaO}_{2}\right)$ and postductal saturation to identify the upper limits for $\mathrm{PaO}_{2}$ at each saturation level. Table 1 gives the limits (mean $+(1.645$ SD)) below which $95 \%$ of values fall. From this it was concluded that saturations above the 93-94\% bracket could be associated with an increased $\mathrm{PaO}_{2}$ value above $11.5 \mathrm{kPa}(87.4 \mathrm{~mm} \mathrm{Hg})$. Preductal saturations greater or equal to $93 \%$ in the presence of a saturation difference of at least $3 \%$ were subsequently viewed as potential preductal hyperoxia.

Table 2 shows the discrepancies between the right hand and foot saturation readings. On 32 occasions the foot reading was higher than the right arm by 1 or $2 \%$; these impossible' recordings presumably reflect the resolution and accuracy of the monitors. The fact that the foot saturation was never more than $2 \%$ above the right hand reinforces our decision to define a shunt as a foot saturation of at least $3 \%$ below that in the right hand. Right to left shunting was identified on at least one occasion in half the infants. Shunting episodes where the preductal saturation was $\geq 93 \%$ (representing possible preductal hyperoxia) occurred in five of the 20 infants.

Examining the infants weighing $<1000 \mathrm{~g}$ or of 24-28 weeks' gestation showed that neither group differed significantly from the heavier or more mature infants (Fisher's test; see table 3).

Of a total of 138 measurements performed on these 20 infants right to left ductal shunting was shown 24 times: $17 \cdot 4 \%$ of occasions (95\% confidence interval 12 to $25 \%$ ).

Table 2 Saturation discrepancies among measurements made

\begin{tabular}{lc}
\hline $\begin{array}{l}\text { Difference in } \\
\text { saturation between } \\
\text { foot and right arm }\end{array}$ & $\begin{array}{l}\text { No of } \\
\text { measurements } \\
(n=138)\end{array}$ \\
\hline+3 or greater & 0 \\
+2 & 13 \\
+1 & 19 \\
0 & 47 \\
-1 & 30 \\
-2 & 5 \\
-3 & 6 \\
-4 & 5 \\
-5 & 3 \\
-6 & 3 \\
-7 & 1 \\
-8 & 1 \\
-9 & 2 \\
-12 & 2 \\
-25 & 1 \\
\hline
\end{tabular}

Table 3 Frequency of right to left shunt among infants studied

\begin{tabular}{llll}
\hline $\begin{array}{l}\text { Characteristic } \\
\text { of infant }\end{array}$ & $\begin{array}{l}\text { No of } \\
\text { infants }\end{array}$ & $\begin{array}{l}\text { No (\%) with } \\
\text { right to } \\
\text { left shunt }\end{array}$ & $\begin{array}{l}\text { No (\%) with } \\
\text { preductal } \\
\text { oxygen } \\
\text { saturation } \geq 93 \%\end{array}$ \\
$\begin{array}{l}\text { Gestation (weeks) } \\
24-28\end{array}$ & 11 & $6(55)$ & 2 \\
$\begin{array}{l}29-32 \\
\text { Weight (g) } \\
\quad 1000\end{array}$ & 9 & $4(44)$ & 3 \\
$\geq 1000$ & 8 & $4(50)$ & 2 \\
All infants & 12 & $6(50)$ & 3 \\
\hline
\end{tabular}

Table 4 Frequency of right to left shunt among measurements made

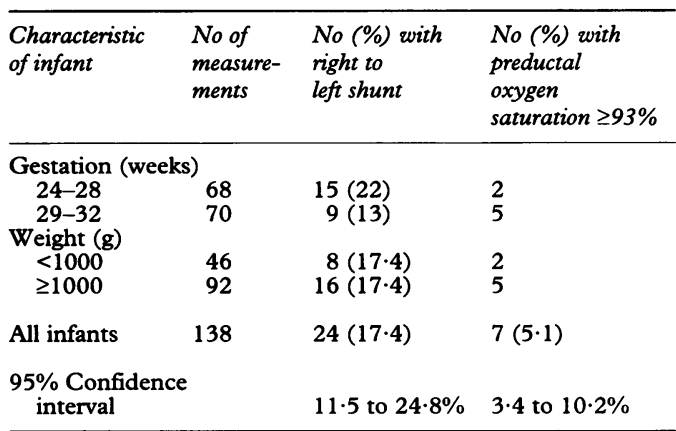

Shunting with preductal saturation $\geq 93 \%$ occurred on seven occasions.

Examining measurements in infants of $<1000 \mathrm{~g}$ or gestation $24-28$ weeks showed no significant difference in the frequency of shunting episodes nor of hyperoxic shunts compared with the measurements in the heavier or more mature infants (table 4).

Three of the infants died due to severe hyaline membrane disease complicated by pulmonary interstitial emphysema. Shunting was seen in all three infants who died compared with seven of the 17 who survived. There was a highly significant increased frequency of shunting in those who died occurring in 11 of 16 measurements compared with 13 of 122 measurements in those who survived $\left(p=2 \cdot 3 \times 10^{-6}\right.$; Fisher's test). One infant died early at 11 hours after birth with evidence of shunting on four of four occasions, but even if his data are excluded the increased frequency remains highly significant $\left(p=5.82 \times 10^{-4}\right)$. The other two infants survived throughout the study and developed shunting later in the 36 hour period as their disease progressed. Only one of the 11 episodes was associated with possible preductal hyperoxaemia.

The most marked example of shunting in an infant who survived was a $1004 \mathrm{~g}, 25$ week gestation infant. She had evidence of right to left ductal shunting on four of seven comparisons with saturation differences of $5,5,3$, and $6 \%$; her highest preductal saturation with evidence of right to left ductal shunt was $92 \%$.

\section{Discussion}

These results confirm that right to left ductal shunting is common in the first 36 hours of life in these premature infants. The primary aim of this study was to identify the extent to 
which postductal arterial blood gas interpretation can be distorted by right to left ductal shunting rather than to document how long such shunts lasted. Such distortion could be occurring in up to $25 \%$ of blood gas samples (upper limit of $95 \%$ confidence interval). Preductal hyperoxaemia occurs much less often, however, and does not appear to be a major problem. Our level of identifying such preductal hyperoxaemia was chosen as a worst possible scenario and is likely to be an overestimate. A substantial number of the shunting episodes occurred in the most severely ill babies who subsequently died of their respiratory disease. We have concentrated on identifying right to left ductal shunting in the more immature infants in whom the dangers of hyperoxaemia are greatest. Neither infants under $1000 \mathrm{~g}$ nor those of 24-28 weeks' gestation differed significantly in their incidence of shunting from the rest of the study sample.

Concern has previously been raised about the possibility of large right to left shunts occurring in premature babies. ${ }^{5}$ Roberton and Dahlenburg studied this problem in 21 infants with hyaline membrane disease by examining paired preductal and postductal arterial gases. ${ }^{1}$ Nine of their infants had discrepancies in $\mathrm{PaO}_{2}$ at times when the postductal $\mathrm{PaO}_{2}$ was within the normal range; only one of these infants was of less than 32 weeks' gestation. Eight of their 21 infants were ventilated at some time but only three appear to have been ventilated during the study period. It is thus difficult to apply their data to the smaller, less mature ventilated infant.
Pearlman and Maisels examined preductal and postductal transcutaneous $\mathrm{Po}_{2}{ }^{3}$ Most of their infants were ventilated but not all. Their results were reassuring, concluding that clinically important differences between preductal and postductal $\mathrm{Po}_{2}$ were infrequent and short lived. Their study enrolled relatively mature infants up to 35 weeks of gestation, however, and only included three infants under $1000 \mathrm{~g}$.

Our results are consistent with those from previous studies but provide additional data relating to the more premature and smaller infants. We are reassured that postductal arterial gas measurements are a safe means of monitoring oxygenation in these infants. Placement of twin oximeter probes on the right hand and a foot appears to be an effective method of identifying right to left ductal shunting. Although preductal hyperoxaemia resulting from such shunts is uncommon, it is reasonable to preferentially use the right hand if using a pulse oximeter in ventilated premature infants.

Roberton NRC, Dahlenburg GW. Ductus arteriosus shunts in the respiratory distress syndrome. Pediatr Res shunts in the resp

2 Rudolph AM, Drorbaugh JE, Auld PAM, et al. Studies on the circulation in the neonatal period. Pediatrics 1961 27:551-66.

3 Pearlman SA, Maisels MJ. Preductal and postductal transcutaneous oxygen tension measurements in premature infants with hyaline membrane disease. Pediatrics 1989 83:98-100.

4 Meier-Stauss P, Bucher HU, Hurlimann R, Konig V, Huch R. Pulse oximetry used for documenting oxygen saturation and right to left shunting immediately after birth. Eur f Pediatr 1990;149:851-5.

5 Gersony WM, Duc GV, Dell RB, Sinclair JC. Oxygen method for calculation of right to left shunt: new application in presence of right to left shunting through the ductus arteriosus. Cardiovasc Res 1972;6:423-8. 